ISSN: 0213-2060

DOI: https://doi.org/10.14201/shhme392203214

\title{
NUEVOS PLANTEAMIENTOS SOBRE EL ARAGONÉS MEDIEVAL
}

\author{
New approaches to medieval Aragonese
}

Inés FERNÁNDEZ-ORDÓÑEZ

Departmento de Filología Española. Facultad de Filosofia y Letras. Universidad Autónoma de Madrid. Campus de Cantoblanco. Cl Francisco Tomás y Valiente, 1. 28049 Madrid. C. e.: ines.fernandez-ordonnez@uam.es. ORCID: https://orcid.org/0000-0003-4512-7761

RESUMEN: En este trabajo se ofrece una síntesis de nuevos planteamientos sobre el estatus sociológico del aragonés medieval en los que se destaca la importancia que adquirió esa lengua en la construcción política del reino de Aragón, en contraste con el catalán y el latín. Se discute asimismo la definición lingüística del concepto de «aragonés común», sobre el que se habría edificado el proceso medieval de estandarización de la lengua, así como los problemas que plantea esa definición.

Palabras clave: aragonés; estandarización lingüística.

ABSTRACT: This work offers a synthesis of a new approach to the sociological status of medieval Aragonese that highlights the importance of this language in the political construction of the kingdom of Aragon, in contrast to Catalan and Latin. The linguistic definition of the concept of Common Aragonese, on which the medieval process of language standardization would have been built, is also discussed, so as the problems that such definition pose.

Keywords: Aragonese; linguistic standardization.

El importante estudio de Guillermo Tomás Faci, El aragonés medieval. Lengua y Estado en el reino de Aragón ${ }^{1}$, viene a colmar de forma brillante una necesidad historiográfica: la existencia de un proceso de estandarización de la lengua de Aragón hasta finales del siglo XIV, superando la consideración, completamente anacrónica, de que ha sido objeto por parte de la filología espańola y catalana, de dialecto "histórico», variante híbrida y carente de uniformidad. La tesis principal, en la que no puedo estar más de acuerdo, es que el aragonés experimentó ese proceso en paralelo a la construcción y desarrollo de

1 Tomás Faci, Guillermo. El aragonés medieval. Lengua y Estado en el reino de Aragón. Zaragoza: Universidad de Zaragoza, 2020. 
sus instituciones feudales (que en el libro se identifican a través del concepto de Estado). Para ello, el autor demuestra un conocimiento amplio y profundo, de primera mano, de la documentación archivística aragonesa, mucha de la cual permanece inédita, además de manejar una extensa bibliografía histórica y filológica. Los datos aducidos superan cualquier estudio previo, la exposición es clara y la redacción fluida y amena.

El marco teórico utilizado para explicar la génesis semiótica de la lengua aragonesa es el proporcionado por las antropólogas Judith Irvine y Susan $\mathrm{Gal}^{2}$ en el cual se distinguen la iconización (o identificación de una variedad como un concepto diferenciado y autónomo asociado a un espacio social y político), el borrado (o extensión de la variedad seleccionada sobre las otras del territorio) y la recursividad fractal (la extensión y empleo de esa identidad gestada en torno a la lengua a otros ámbitos del que surgió como elemento de cohesión identitaria y de afirmación política). Si bien con otros términos, parte de estos conceptos son bien conocidos por los sociólogos del lenguaje y lingüistas variacionistas para explicar la diferenciación entre lenguas y dialectos y la creación de normas o estándares lingüísticos. El proceso que se aborda en el libro no es tanto la génesis de una norma o estándar oral - existente en cualquier colectividad lingüística, incluso en la tribales_-, sino más bien la emergencia de una lengua estándar, la cual siempre está vinculada a la aparición de una escritura semifonológica y no ha sido experimentada por multitud de lenguas del mundo, sin que por ello sus hablantes dejen de considerarlas lenguas autónomas o históricas ${ }^{3}$. En la estandarización se suelen distinguir las siguientes dimensiones: seleccción de variedad lingüística e identificación de la misma, superposición a las demás variedades, que paulatinamente pasan a ser subestándar, capacitación, elaboración o normalización (extensión progresiva de la variedad a todo tipo de discursos textuales y situaciones comunicativas, con el apoyo decidido de las élites sociales), codificación o normativización (elaboración de códigos que regulan de forma explícita el uso lingüístico) y regulación legal (cuando la lengua forma parte de los derechos y deberes políticos de los individuos). Hay que esperar al Renacimiento para que empiecen los intentos de codificación y a la Edad Moderna para que se trate jurídicamente el uso lingüístico, por lo que en la Edad Media solo se encuentra una codificación y una regulación de facto, por la vía de los hechos, en la práctica escrita de los textos. No obstante, el resto de dimensiones de la estandarización pueden detectarse ya, aunque con importantes diferencias, en las lenguas romances peninsulares que comenzaron este proceso: gallegoportugués, castellano, navarro, aragonés y catalán. Este libro construye el relato de la estandarización fallida del aragonés tratando algunas de estas facetas e incide sobre todo en los factores políticos e institucionales que determinaron la emergencia del proceso y su fracaso. Aunque está presente, no se concede tanta importancia ni espacio a la capacitación, esto es, al empleo del definido como «aragonés común» fuera del ámbito

2 Irvine, Judith y Susan Gal. «Language ideology and linguistic differentiation». En Kroskrity, P. V. (ed.). Regimes of language ideologies, polities and identities. Santa Fe: School of America Research Press, 2000, pp. 35-83.

3 Cf. el clásico trabajo de Joseph, John E. Eloquence and power: The Rise of Language Standards and Standard Languages. Londres-Nueva York: Frances Pinter \& Blackwell, 1987, o la síntesis de Amorós Negre, Carla. Las lenguas en la sociedad. Madrid: Síntesis, 2014. 
administrativo, notarial y político — con la salvedad de la producción de Juan Fernández de Heredia_, ni a la falta de respaldo de esa variedad por parte de las élites intelectuales y sociales del reino desde el siglo Xv en adelante, aspectos que sabemos imprescindibles para alcanzar una estandarización plena y que deciden, todavía hoy, en gran medida el éxito de las políticas lingüísticas que conducen a ella (tenemos no pocos ejemplos en la Espańa contemporánea). En definitiva, el grado de capacitación revela en qué medida la comunidad lingüística se identifica y promueve la variedad en cuestión.

El libro se estructura en cuatro capítulos. El primero se dedica a explicar la gestación del espacio político y social donde surge la lengua aragonesa, su emergencia escrita frente al latín y el nacimiento de su conciencia diferencial como aragonés («iconización»). Como resultado de la expansión conquistadora y colonizadora del reino pirenaico, como es bien sabido, en Aragón se distinguen el altoaragonés pirenaico, el bajoaragonés del valle del Ebro, en el que intervino la nivelación dialectal de pobladores de orígenes variados, y el de la serranía ibérica, en el que fue sustancial el componente de origen navarro, por lo que la nivelación obtuvo otros resultados, similares al castellano de tipo oriental. Aunque hay testimonios de lengua romance transcrita con ortografía semilatina desde finales del siglo XII — como en otros territorios ibéricos—, la adopción general de una ortografía semifonológica del romance en la documentación aragonesa tiene lugar tardíamente, hacia 1270, con la excepción de algunos ejemplos en monasterios cercanos a Navarra y del occitano empleado en Jaca, como analiza el autor. En su opinión, la ortografía romance fue un cambio impulsado por los juristas aragoneses que dominaban el latín y el derecho. Los Fueros de Aragón compilados por el obispo Vidal de Canellas en 1247 habrían sido escritos en romance o, al menos, traducidos tempranamente al romance en la segunda mitad del siglo XIII, antes de su reformulación latina hacia 1300, en coherencia con la emisión en romance de códigos jurídicos asociados a un espacio político como el Fuero general de Navarra, el Fuero real castellano, los Usatges catalanes o los Furs de Valencia. Como bien ve Tomás, los fueros representan el primer esfuerzo por gestar un código lingüístico aragonés vinculado a un espacio político y ofrecen el contexto discursivo que permite desarrollar una conciencia idiomática. Los manuscritos muestran divergencias gráficas, pero implican un esfuerzo significativo de desarrollo de una lengua culta en la sintaxis y el léxico. El manuscrito navarro del Vidal Mayor, de finales del siglo XIII, la compilación extendida y comentada de los Fueros de Vidal de Canellas, contiene la primera mención metalingüística al lengoage de Aragón y muestra la conexión del espacio jurídico y político de los Fueros con la variedad románica propia de ese territorio, identificada por primera vez con un gentilicio. Gran aportación de este estudio es haber localizado multitud de menciones a la lengua aragonesa, a veces llamada aragonés, que revelan la existencia de una conciencia idiomática diferencial entre finales del siglo XIII y hasta la década de 1470, manifiesta en la emisión bilingüe de documentos o acuerdos de la cancillería en aragonés y catalán y, en menor medida, en castellano y aragonés.

El segundo capítulo versa sobre la creación de una norma escrita del aragonés, una scripta aragonesa, que el autor bautiza con el nombre de «aragonés común», y cuya existencia es, sin duda, la hipótesis fundamental de este estudio. Esa norma de uso escrito que se empleó hasta 1475 se basó sobre el dialecto de Zaragoza, claramente divergente 
del altoaragonés y del bajoaragonés del Sistema Ibérico (y del de la Castellanía de Amposta, empleado a menudo en los textos promovidos por Juan Fernández de Heredia a finales del siglo XIV). Generalizado en la documentación notarial e institucional de los delegados de la Corona (merinos, bailes, recaudadores), fue difundido a esas otras zonas del reino, que, a partir de 1300, comienzan a revelar su influencia como modelo de prestigio (desencadenando un «borrado» de las variedades locales). Asimismo, esa variedad era usada en los contextos orales de cierta formalidad, como los discursos reales ante las Cortes, y hubo de constituirse en modelo de la lengua oral elaborada entre las élites del reino. El autor reconoce que la relativa uniformidad del paradigma del aragonés común solo se encuentra en la documentación institucional y notarial, mientras que otros textos importantes en aragonés — sobre todo para su capacitación, como los de Heredia- no siempre se ajustan a ese patrón. G. Tomás define el aragonés común a partir de la selección de tres rasgos de evolución fonética y cuatro morfológicos, que, en su opinión, resultaron de la elección de soluciones gráficas convencionales ya existentes en las lenguas vecinas. $1^{\circ}$-KT-, ULT- evolucionan a [-jt-], como en navarro y altoaragonés, feyto, frente al castellano, fecho, y catalán, fet. El aragonés de la serranía empleaba la misma solución que en Castilla, tempranamente extendida también en Navarra. $2^{\circ}$ La palatalización de -K'L-, -LY- en $[K]$, como en filla, al igual que en catalán, altoaragonés y navarro, frente al castellano y aragonés serrano fija, solución también difundida por Navarra ya en el siglo XIII. $3^{\circ}$ Evolución de los diptongos resultantes de Ě y ŏ tónicas latinas a [je] y [we], como en castellano y navarro, fuente, tierra, frente a la ausencia de diptongación en catalán, font, terra, y a la diptongación, solo propia del Alto Aragón, en [ja, wa], fuant, tiarra. $4^{\mathrm{o}}$. El paradigma del artículo castellano y navarro, el, frente al empleo de lo en el Alto Aragón y el catalán medieval. $5^{\circ}$ Evolución de las desinencias de imperfecto de indicativo de la segunda y tercera conjugaciones -EBAM, -IBAM, a - $i$ a, tal como en castellano, navarro o catalán, que estima un convencionalismo gráfico de la norma culta, frente a las formas populares que aparecen esporádicamente y mantienen la labial (como en feva o exiva). $6^{\circ}$ Formación del plural de los singulares acabados en consonante sin apócope, como en castellano y navarro, lugares, frente al catalán y altoaragonés lugars, que atribuye también a una convención ortográfica habida cuenta de la presencia de las formas apocopadas de forma esporádica en todo el reino. $7^{\circ}$ Presencia de las desinencias de $2^{a}$ persona del plural -des, como en castellano, navarro y aragonés de la serranía, sodes, frente a las soluciones apocopadas del catalán medieval y del altoaragonés actual (sots, sotz, soz), que supone las generales en la oralidad antigua. Esta selección de rasgos se aplica en el libro a todas las muestras documentales para decidir qué es o no aragonés común o modelo idiomático del reino. Aunque se reconoce que el aragonés meridional, representado por los documentos privados de esa zona, la Castellanía de Amposta y parte de los textos de Fernández de Heredia, no se sometió a ese patrón, se desvirtúa su importancia en tanto que no fue utilizado en las instituciones aragonesas. Con todo, no está de más observar aquí que solo los dos primeros de los siete rasgos aducidos, ambos de carácter fonético, eran discrepantes con el castellano y que esa divergencia ni siquiera tenía lugar en la scripta del aragonés meridional. El capítulo aborda asimismo el empleo del occitano en Jaca y del catalán en la Franja, zona en que la scripta era catalana a pesar de que significativamente, en determinadas circunstancias, como en la representación en las Cortes, se 
emitían las cartas de poderes en aragonés, en vista de la jurisdicción institucional a que ese territorio pertenecía.

El tercer capítulo está dedicado a exponer, con multitud de datos, la dimensión política que adquirió la lengua dentro de la Corona de Aragón, una monarquía compuesta de distintos reinos que constantemente hicieron valer sus derechos y reivindicaciones apoyándose en la identidad diferencial que connotaba el uso de una lengua y no de otra («recursividad fractal»). Como Estado políglota, la monarquía aragonesa manejó tres lenguas escritas: el latín, el aragonés y el catalán. Aquí se ofrece un minucioso análisis que, siguiendo la estela de los estudios pioneros de Germán Colón y Fernando Gonzalez Ollé, describe qué circunstancias decidían la selección de una u otra por parte de los distintos integrantes del reino. La distinción entre las dos lenguas romances se pone de manifiesto entre los juristas ya desde la primera mitad del siglo XIII y se reproduce en múltiples instancias como prueba del dualismo jurídico y étnico de los regnícolas. Desde finales del siglo XIV, y en la medida que Valencia se convierte en actor político equivalente a Aragón y Cataluña dentro de la Corona, aparece también el concepto de lengua valenciana, citada en contraste con el aragonés y el catalán. El abandono del latín a favor del romance fue relativamente tardío en Aragón, en comparación con otros ámbitos ibéricos, pero desde 1260 se extiende al notariado público, a la administración económica de la monarquía y al Mestre Racional (una especie de interventor general de las cuentas públicas), así como a los delegados del rey, como bailes, merinos y sobrejunteros. Sin embargo, tanto la administración de justicia como la documentación expedida por la cancillería regia mantuvieron el latín durante toda la Edad Media (hasta el siglo xviII en el caso del Justicia de Aragón), como sucedía en Francia. Cuando se empleaba el vernáculo desde la corte del rey, la elección de aragonés y catalán estaba regida por los siguientes principios: el catalán era la lengua propia del núcleo institucional de la monarquía, en la que Barcelona actuaba de hecho como capital administrativa, mientras que los funcionarios e instituciones que intervenían en cada territorio recurrían a la lengua empleada por sus integrantes, catalán en Cataluña, Valencia y Mallorca, aragonés en Aragón. El rey empleaba el latín como lengua neutra en disposiciones generales a todos sus súbditos, como gesto de autoridad, mientras que el vernáculo hacía acto de presencia en cartas dirigidas a destinatarios específicos como signo de proximidad hacia ellos. Desde 1259, Jaime I empieza a dirigirse en romance a los grandes aristócratas catalanes y aragoneses y a los infantes aliados con ellos, además de emplearlo en su correspondencia con otros reinos ibéricos, práctica que no se alteró en los reyes sucesivos, si bien creció muy lentamente la proporción de romance respecto del latín, siempre mayoritario. Desde mediados del siglo XIV, y en el contexto de la guerra con Castilla, Pedro IV inicia una política de vernacularización en las dos lenguas de uso de su monarquía, el aragonés y el catalán, como acto de propaganda de su política regalista entre las élites del reino. Ello se refleja en la documentación cancilleresca,

4 Colón Domènech, Germà. El español y el catalán, juntos y en contraste. Barcelona: Ariel, 1989. González Ollé, Fernando. "Distinción legal entre castellano y aragonés en 1409». Revista de Filología Española, 1983, vol. 63, n. ${ }^{\circ} 3-4$, pp. 313-314; «Opciones y preferencias lingüísticas del rey Pedro IV de Aragón». Revista de Filología Española, 2007, vol. 87, n. 2 2, pp. 293-322; "Actitudes lingüísticas de los reyes de Aragón». En Lagüens, Vicente (ed.). Baxar para subir. Colectánea de estudios en memoria de Tomás Buesa Oliver. Zaragoza: Institución Fernando el Católico, 2009, pp. 85-110. 
que a partir de ese momento se vuelve trilingüe: latín para disposiciones generales y vernáculo para las confidenciales o específicas de un colectivo. Desde entonces, el mismo documento podía expedirse en aragonés o catalán según el destinatario. Reflejo de esta práctica introducida por el Ceremonioso es la existencia de copias de las Ordinaciones de la Casa Real de 1344-1353 destinadas a Aragón, Cataluña y Valencia, cada una en la lengua de esos territorios, así como copias en latín, aragonés y catalán de la Crónica real (h. 1369-1372). Este bi- o trilingüismo se manifestaba asimismo en las Cortes Generales, habitualmente reunidas en Monzón. Allí el rey pronunciaba su proposición en catalán y era respondido por los representantes en aragonés, esquema que revela el mayor poder simbólico y político que tenía la primera de las lenguas. En consecuencia, puesto que el latín o el catalán era la lengua del rey, el empleo del aragonés se convirtió en un emblema de la resistencia política y voluntad de autonomía de la aristocracia y concejos de ese reino ante el poder regio. Por otra parte, en los territorios en que había discrepancia entre la lengua de uso y la adscripción jurídica (por ejemplo, en la Franja o en las tierras del interior de Valencia), prevalecía la lengua allí hablada si el documento se expedía solo para esa zona, pero si era una disposición general para ese reino (Aragón o Valencia), se recurría al idioma en él general (aragonés o catalán). Por último, se prueba la existencia de una conciencia idiomática aragonesa diferencial de la variedad navarra (según se ve en la Crónica de los Estados peninsulares, de 1305) y de la castellana (desde la época de Pedro IV, mediados del siglo XIV), pese a la similitud de muchos rasgos lingüísticos. En cambio, desde el centro peninsular se percibía ante todo la divergencia lingüística catalana. De la extensa, rica y pormenorizada exposición del autor resulta claro que, cuando se introdujo el vernáculo en la cancillería regia, la lengua se seleccionaba de acuerdo con el destinatario, proceso de acomodación que revela una monarquía que nunca quiso imponer a los distintos componentes de su reino su opción lingüística (del mismo modo que no pretendió integrarlos bajo una unificación jurídica). Y esa acomodación se extendía asimismo a la correspondencia regia con los otros reinos ibéricos, para la que se seleccionaba el aragonés (incluso a veces interferido con el castellano), pero nunca el catalán o el latín (empleado este último para escribir a Francia o Italia). La lectura política de esta última práctica no es obvia, pero, a juicio del autor, descubre la voluntad de aproximación de Aragón al espacio ibérico, «una estrategia para que la Corona de Aragón reforzase su integración simbólica y práctica en el ámbito hispano» (p. 208).

El cuarto capítulo aborda la castellanización de la scripta aragonesa y las condiciones que la desencadenaron. Es bien sabido que en la adopción de rasgos castellanos en la lengua escrita aragonesa con la consiguiente decadencia del aragonés y del catalán escritos fue determinante el compromiso de Caspe y la entronización de una dinastía castellana en la Corona de Aragón. El proceso se desencadenó, sobre todo, a partir de 1435, como relata el autor, en la corte napolitana de Alfonso V el Magnánimo, cuando las élites intelectuales aragonesas se familiarizaron con el castellano y, difundido el ejemplo a la Península, comenzó a escribirse literatura en esa lengua en Aragón. Desde esa fecha, en la cancillería poco a poco se produjeron documentos híbridos en castellano y aragonés y la primera scripta se hizo mayoritaria hacia 1470. No obstante, la conciencia lingüística diferencial se mantuvo en la cancillería: la última alusión al aragonés como entidad diferenciada es de 1467 (sin que el autor pueda descartar otras posteriores) y la primera al 
castellano de 1448. Pero fue entre 1480 y 1500 cuando se consumó la desaparición de los rasgos fonéticos típicos de la scripta aragonesa en la cancillería, que fue seguida por los documentos notariales locales: por tanto, en época de los Reyes Católicos, cuando los reinos se unieron bajo un único paraguas dinástico. Como muestra el autor, por la misma época algunos autores consideraban ya castellano y aragonés una misma lengua. Esta suplantación (o evolución) de la lengua de la cultura escrita hubiera sido imposible sin la colaboración activa de las élites del reino que adoptaron el castellano como signo de prestigio social. Pese a ello, todavía entre los siglos XVI y XVIII algunos siguieron recurriendo al concepto identitario de «lengua aragonesa» como definitoria de la variedad, ahora lingüísticamente "castellana», escrita en Aragón. Esa coincidencia formal no había impedido que todavía en las Cortes Generales de 1510 se hablara de «lengua aragonesa». A partir de ese momento, tuvo lugar el desprestigio de las variedades pirenaicas y se reclamó para la lengua hablada en Aragón el mismo abolengo y consideración que tenía la de Castilla. La voluntad de mantenimiento de las instituciones aragonesas no se acompañó de la defensa de la lengua antigua ni de su continuación, las hablas del norte de Huesca, sino de la variedad "castellanizada» hablada en el centro y el sur del dominio.

Las novedades y aportaciones del libro, además de la síntesis de trabajos previos y documentación bibliográfica, son extraordinarias y, en general, muy acertadas en su interpretación y construyen una historia sociopolítica del aragonés medieval de la que estábamos necesitados. Aun así, debo hacer constar aquí algunas de mis discrepancias.

Un problema del libro es que reduce la historia lingüística a los procesos que conducen a la estandarización de las lenguas, en los que habitualmente se manifiestan las relaciones de poder que tienen lugar de arriba abajo en la escala social. Se olvida, sin embargo, que la historia lingüística no es solo la historia de las lenguas estándar — gran parte de las lenguas del mundo no han experimentado procesos de estandarización y el estándar es un constructo sociocultural, un dialecto que no es la lengua materna de nadie-. Los cambios lingüísticos no siempre están guiados por relaciones verticales en que se ejerce la violencia simbólica del poder, sino que el contacto y la comunicación horizontal entre los hablantes también subyacen a la evolución lingüística, incluso de la lengua estándar. Es innegable que las relaciones de poder influyen en la adopción de los cambios lingüísticos (no se generaliza nada que no es prestigioso y el prestigio lo suelen definir los grupos de hablantes con poder), pero lo prestigioso no siempre está conscientemente decidido desde arriba, salvo quizá en las políticas lingüísticas que conducen a la creación de las lenguas estándar. Los sociolingüistas saben bien que el contacto y las vías de comunicación son determinantes en la difusión de las innovaciones, que estas también pueden extenderse desde «abajo» y operar de forma compleja a través de la estructura social, y que la imposición de formas lingüísticas de nada sirve sin que la comunidad afectada acepte esa «violencia». De lo contrario, sería imposible explicar la difusión y generalización de innovaciones lingüísticas desaconsejadas por el «poder» académico, político, social o económico, que, muchas veces, acaba adoptándolas forzado por su generalización en la comunidad; de lo contrario, sería inexplicable que las lenguas europeas de distintas familias lingüísticas, claramente identificadas, estandarizadas y reguladas por estados, compartan rasgos desconocidos del resto de lenguas del mundo y difundidos en época moderna; de lo contrario, no podría explicarse la génesis de multitud de áreas lingüísticas dialectales 
que no dependen de intervenciones políticas medievales o modernas (como sí lo fueron la conquista, la colonización o la imposición de una variedad escrita desde el poder, procesos que, por supuesto, también dan lugar a áreas geolectales). El contacto, bien entre hablantes letrados, bien entre hablantes no letrados, bien entre hablantes de distinta adscripción social, es determinante en la difusión de formas lingüísticas, así como es decisivo el cambiante valor que estos les atribuyen.

A este propósito, un aspecto que no se sopesa en el libro es que la castellanización de la scripta pudo no ser solo exógena y resultado de la "cultura hegemónica» en castellano, sino también obedecer a un cambio en la variedad de aragonés que se tomó como modelo de la lengua escrita. Desde las primeras emisiones documentales, el aragonés meridional, de la serranía ibérica y de las tierras valencianas, coincidía en gran parte de sus rasgos lingüísticos con el navarro y el castellano. Y precisamente son esas tierras del Bajo Aragón y Valencia las que ganan importancia demográfica, económica y política a lo largo del siglo xv. Si atendemos a los rasgos que, según el autor, caracterizan al aragonés "común», solo dos de los siete aducidos, de carácter fonético, eran diferenciales con el castellano (y el navarro había alternado esas soluciones con las castellanas ya desde el siglo $\mathrm{XIII})$, mientras que el resto era coincidente. El cambio de scripta bien pudo ser favorecido por una sustitución de la variedad aragonesa que definía la lengua escrita.

Tampoco se valora que es justamente en el siglo xv, de forma paralela a la «castellanización» de los rasgos aludidos de la scripta, cuando los grupos dirigentes aragoneses aumentaron su capacidad de difundir el modelo lingüístico que empleaban. Ya desde antes de 1412 las variedades del oriente peninsular — aragonés y catalán- habían adoptado soluciones lingüísticas innovadoras que solo se generalizaron en castellano a partir del siglo $\mathrm{XV}$, precisamente cuando se aproximaron las coronas y las cortes de los dos reinos, se incrementó la influencia castellana sobre Aragón, pero también la aragonesa sobre Castilla. Para negar este hecho, la «aragonesización» de Castilla en esta época — que obviamente no es de la misma naturaleza jerárquica que el proceso inverso, sino que opera de forma transversal a través del cada vez más intenso contacto entre los hablantes de los dos ámbitos_-, el autor limita su concepto de aragonés a su definición apriorística del mismo - basada en unos pocos rasgos fonéticos y morfológicos- Se descarta así de antemano la idea de que la scripta aragonesa contuviera soluciones lingüísticas desconocidas de Castilla y que, irradiadas desde el oriente peninsular, se adoptaran en el centro. No contempla la posibilidad de que las élites aragonesas cada vez más próximas a las de Castilla o finalmente integradas en la corte, desde la época de los Reyes Católicos, tuvieran la más mínima capacidad de influir en la construcción del español estándar ni condicionar el prestigio de las formas lingüísticas que se generalizaron en él. Los datos históricos y lingüísticos, sin embargo, no avalan este planteamiento. Aragón fue determinante en la relatinización e italianización del vocabulario desde el siglo xv, el desarrollo de los tratamientos, la generalización de los tiempos compuestos o en la aparición de multitud de conectores discursivos y cuantificadores. Pudo perder algunos rasgos fonéticos diferenciales, pero otros aspectos característicos que no se sintieron ajenos se abrieron camino y se expandieron fuera de los límites del reino. Por muy castellanizada que estuviera la scripta aragonesa en los rasgos seleccionados por el autor, hasta 1470 (el reinado de los Reyes Católicos) podemos considerarla el legítimo representante de la lengua culta aragonesa. 
Y ese dialecto escrito («castellano» o "castellanizado», según el autor, o «aragonés»si atendemos a la identidad derivada de los contextos de emisión) irradiado desde la Corona de Aragón fue un modelo lingüístico capaz de difundir sus opciones y transformar en muchos aspectos el castellano medieval en el español moderno.

Y aquí está uno de los grandes problemas del libro: la definición de la norma estándar aragonesa, el «aragonés común» consagrado en la scripta, que resulta impresionista, apriorística y más afirmada que demostrada con datos cuantitativos en los ejemplos documentales en que se aduce. En ello el autor parece seguir el modelo interpretativo creado por R. Menéndez Pidal para la historia del espańol, repetido posteriormente por multitud de autores $(v \cdot g r$. R. Penny o R. Wright), de acuerdo con el cual en la corte de Alfonso X se habría gestado una norma lingüística que se difundió a todo el reino de Castilla y León, norma que, sin embargo, los estudios empíricos modernos se encargan una y otra vez de relativizar. A este propósito, este libro se atiene en su forma de clasificar las variedades al modelo de la filología románica decimonónica —que introdujo Menéndez Pidal y se ha repetido hasta la saciedad - que recurre fundamentalmente a rasgos fonéticos de existencia / ausencia para definir la variedad considerada. En un análisis lingüístico moderno, las variedades no solo se definen por rasgos de presencia / ausencia sino por los porcentajes de uso de cada variante definidos en contextos concretos (por ejemplo, la apócope se gradúa del oriente peninsular al centro según el tipo de vocal final, si va seguida de consonante, según la clase de palabras afectada, etc.). El aragonés puede coincidir en el resultado con otras áreas peninsulares, pero la disimilitud radicar en el porcentaje y los contextos de uso. Y aquí es importante recordar que la variación no «degrada» la lengua ni la scripta, si bien es cierto que los historiadores de la estandarización lingüística tienden a enfatizar la uniformidad desde un presupuesto puramente ideológico. Al no analizar estadísticamente la presencia de soluciones lingüísticas alternantes en el «aragonés común» (probablemente para evitar la impresión de falta de uniformidad que deriva de las descripciones de los lingüistas), en este estudio se oculta que las soluciones supuestamente «foráneas», por coincidentes con territorios situados más al oeste, pudieran haberse difundido y aceptado tempranamente en Aragón, y no solo en la Serranía, o incluso gestado en el territorio, y, por tanto, formar parte legítima del «aragonés común», antes de que pudiera haber actuado cualquier castellanización dirigida desde arriba.

Un ejemplo de los problemas a que conducen estas asunciones apriorísticas se da en las desinencias de $2^{\text {a }}$ personal plural en -des, que se suponen sin tradicionalidad en el habla y adoptadas en la scripta aragonesa por presión del modelo castellano en lugar de las apocopadas y plenamente aragonesas, escritas $-t c ̧,-c,-z$, y ello a pesar de que ambas alternan en los documentos en todo el periodo y las primeras son las únicas documentadas en el aragonés de la serranía ibérica. Parece claro que la diferencia no era tanto geográfica sino diastrática: -des tenía un prestigio del que carecía la variante apocopada, pero ambas alternaban. Sin embargo, a partir de esa naturaleza "foránea» atribuida a las desinencias en -des, se postula que, más tarde, durante el proceso de castellanización, habrían perdido la $-d$ - siguiendo el modelo de Castilla. Sin embargo, las investigaciones sobre la historia de estas desinencias en documentos medievales de la península ibérica demuestran que la $-d$ - se perdió tempranamente en el Bajo Aragón desde el siglo XIV y que desde esa área 
se extendió al centro peninsular solo en el siglo $\mathrm{xv}^{5}$. Difícilmente puede tener la pérdida de la - $d$ - un origen castellano o ser síntoma de castellanización, como se pretende, sino quizá de la difusión de un rasgo bajoaragonés que se hizo prestigioso, primero en Aragón y posteriormente en Castilla. En este caso, el aragonés o el modelo dialectal del «castellano» aragonés fue el que se difundió a Castilla (y no al revés).

Algo parecido sucede con las desinencias de imperfecto de indicativo de la segunda y tercera conjugación, que en aragonés común se formulan en -ia, solución que G. Tomás supone adoptada de las scriptae vecinas, castellana o catalana, frente a la genuinamente aragonesa en -eva o -iva, que aparece esporádicamente por todo el territorio y que no se escribiría por su carácter poco culto. Sin embargo, la desinencia en -ía fue seguramente genuina en Aragón, y no importada, pues es la general en Navarra, donde nunca encontramos la solución con labial, y poco usada en el territorio central peninsular que, desde La Rioja hasta el oriente de León, empleaba mayoritariamente -ié en el siglo XIII ${ }^{6}$. El cambio de prestigio en la scripta castellana que hizo reemplazar la solución -ié por -ía en el siglo XIV seguramente no partió de Castilla, sino del oriente peninsular. En este relato de la historia lingüística dependiente solo de las relaciones de poder institucional, se olvida además que las variedades orales subestándar habladas en Aragón se difundieron hacia el sur y el centro peninsular superando con creces los límites políticos de su reino, tanto en época medieval como moderna y que, en muchas ocasiones, encontraron su camino hacia la lengua culta. Aunque las formas en -eba o -iba nunca lo hicieron, no está de más recordar que los imperfectos en -iba (de probable motivación analógica y no etimológica) también se extienden por todo el castellano oriental —áreas que nunca fueron aragonesas-y aparecen además de forma esporádica en el judeoespañol, el dominio asturleonés, Andalucía, Canarias y América ${ }^{7}$.

Sorprende un poco que en esta sociología lingüística de Aragón apenas se considere el contraejemplo de Navarra. Navarra desarrolló tempranamente una conciencia idiomática y una scripta propia y la mantuvo en uso hasta finales de la Edad Media, estrechamente vinculada a sus instituciones forales. Sin embargo, ya desde el siglo XIII la evolución de la lengua navarra convergió en multitud de aspectos fonéticos con el castellano. La «castellanización» lingüística en Navarra operó mucho antes que la anexión política y esa evolución no impidió que se mantuviese la conciencia identitaria de un romance navarro ${ }^{8}$. La historia lingüística de Navarra nos revela que ciertos rasgos centrales

5 Del Barrio de la Rosa, Florencio. «Sociodialectología histórica de las desinencias de 2a persona plural en el español peninsular europeo. Transmisión, difusión y divergencia dialectal». En Garrido Martín, Blanca, Moral del Hoyo, María del Carmen y Raab, Mathias (eds.). Variación diatópica y morfosintaxis en la historia del español. Santiago de Compostela: Universidade de Santiago de Compostela, 2021, pp. 221-254. Rodríguez Molina, Javier. «La reducción fonética avemos cantado>hemos cantado en español antiguo. Nuevos datos y nuevas hipótesis». En Pato, Enrique y Rodríguez Molina, Javier (eds.). Estudios de filología y lingüistica españolas: nuevas voces en la disciplina. Berna: Peter Lang, 2012, pp. 167-234.

6 Moral del Hoyo, M. ${ }^{a}$ del Carmen. «El castellano en los orígenes del cambio gramatical: el pretérito imperfecto de la $2^{\mathrm{a}}$ y $3^{\mathrm{a}}$ conjugación (-ié-/-ia)». En Kabatek, Johannes y Benito Moreno, Carlota (eds.). Lingüistica de corpus y lingüística histórica iberorrománica, Berlín-Boston: Mouton de Gruyter, 2016, pp. 322-357.

Pato, Enrique. "Queriba una cosa y traíba otra. Los pretéritos imperfectos analógicos en español». Philologica Jassyensia, 2018, vol. 14, n. ${ }^{\circ}$ 2, pp. 83-100.

8 Martínez Pasamar, Concepción y Tabernero Sala, Cristina. Hablar en Navarra. Las lenguas de un reino (1212-1512). Pamplona: Gobierno de Navarra, 2012. 
tuvieron capacidad difusora hacia el este, por encima de las fronteras políticas. De modo parejo, hubo otros orientales que se difundieron desde Aragón hacia Navarra y el centro peninsular, tanto en época medieval como moderna?.

Por último, no está de más mencionar que la estandarización cristaliza socialmente las lenguas, cohesiona el grupo de hablantes y proyecta su identidad, pero como proceso dirigido desde el poder no es suficiente si no recibe el respaldo de los hablantes. Aunque aceptemos la existencia de una conciencia idiomática aragonesa construida sobre una scripta en la Edad Media, esta scripta apenas parece haberse extendido a otros ámbitos que los dominados por los juristas, según se descubre en el libro. La aplicación de esta scripta en los textos heredianos es muy limitada (el autor la reduce al Libro de los emperadores) y no se vio reforzada por una producción textual extensa de emisores variados, en todo tipo de discursos y ámbitos del saber, que no dependiera del poder institucional: aparte de la documentación notarial, la lista que la ilustra se compone de los Fueros de Aragón, el Ceremonial de coronación de los reyes de Aragón y la Crónica real de Pedro IV, además de la traducción del Libro del Tesoro de Brunetto Latini. En definitiva, la capacitación del aragonés "común", en la visión del autor, resulta muy precaria, comparada con la del castellano y el catalán. Ello se debe en gran parte a haber excluido del análisis de la scripta textos de clara impronta aragonesa — quizá por no someterse al modelo lingüístico propugnado-. Aparte de los heredianos que no siguen el patrón del «aragonés común», sorprende que nunca se mencione la tempranísima Razón de amor, de principios del siglo XIII, junto a los Diez Mandamientos, la Estoria de los godos (traducción de la Historia Gothica de Jiménez de Rada realizada a instancias de los señores de Albarracín hacia 1252-1253), u otros textos en que los copistas, al menos, fueron aragoneses: el Libro de Apolonio, la Vida de Santa Maria Egipciaca o el Libro de los tres reyes de Orient, la versión del Tristán de Leonis (de h. 1400) o la traducción trecentista del Libro de las maravillas del mundo de Juan de Mandeville, por citar solo algunos de los atribuidos a ese origen lingüístico en la Biblioteca digital del Hispanic Seminary of Medieval Studies ${ }^{10}$. Una visión menos estrecha de la scripta aragonesa, más abierta a una conciencia idiomática que pudiera incluir rasgos lingüísticos supuestamente foráneos, hubiera permitido demostrar que la capacitación del aragonés medieval no fue despreciable y que recibió apoyo de variados tipos de hablantes letrados, aparte del procedente del «Estado». El peso e influencia de estos hablantes excluidos de la scripta del aragonés común no se valora en el libro, pero bien pudieran haber sido decisivos en la evolución de la lengua desde el siglo xv. La historia lingüística está condicionada indudablemente por la sociología del uso y por los valores que las comunidades lingüísticas le confieren, pero estos no son una simple proyección de la historia política, como en ocasiones parece asumirse en este, por lo demás, magnífico ensayo.

9 Fernández-Ordóñez, Inés. La lengua de Castilla y la formación del español. Madrid: Real Academia Española, 2011; «Dialectología histórica de la Península Ibérica». En Dworkin, Steven, Clavería Nadal, Gloria y Octavio de Toledo y Huerta, Álvaro (eds.). Lingüistica histórica del español / The Routledge Handbook of Spanish Historical Linguistics, Londres-Nueva York: Routledge, en prensa.

10 Gago Jover, Francisco, Kasten, Lloyd y Nitti, John (eds). Textos navarro-aragoneses. Digital Library of Old Spanish Texts. Hispanic Seminary of Medieval Studies. On line at http://www.hispanicseminary. org/t\&c/ac/index.htm., 2011 [Septiembre, 2021]. 


\section{REFERENCIAS BIBLIOGRÁFICAS}

Amorós Negre, Carla. Las lenguas en la sociedad. Madrid: Síntesis, 2014.

Colón Domènech Germà. El español y el catalán, juntos y en contraste. Barcelona: Ariel, 1989.

Del Barrio de la Rosa, Florencio. «Sociodialectología histórica de las desinencias de 2a persona plural en el español peninsular europeo. Transmisión, difusión y divergencia dialectal». En Garrido Martín, Blanca, Moral del Hoyo, María del Carmen y Raab, Mathias (eds.). Variación diatópica y morfosintaxis en la historia del español. Santiago de Compostela: Universidade de Santiago de Compostela, 2021, pp. 221-254.

Fernández-Ordóñez, Inés. La lengua de Castilla y la formación del español. Madrid: Real Academia Española, 2011.

Fernández-Ordónez, Inés. «Dialectología histórica de la Península Ibérica». En Dworkin, Steven, Clavería Nadal, Gloria y Octavio de Toledo y Huerta, Álvaro (eds.). Lingüistica histórica del español / The Routledge Handbook of Spanish Historical Linguistics. Londres-Nueva York: Routledge, en prensa.

Gago Jover, Francisco, Kasten, Lloyd y Nitti, John (eds). Textos navarro-aragoneses. Digital Library of Old Spanish Texts. Hispanic Seminary of Medieval Studies. On line at http://www.hispanicseminary.org/t\&c/ac/index.htm, 2011.

González Ollé, Fernando. "Distinción legal entre castellano y aragonés en 1409». Revista de Filología Española, 1983, vol. 63, n. ${ }^{\circ}$ 3-4, pp. 313-314.

González Ollé, Fernando. «Actitudes lingüísticas de los reyes de Aragón». En Lagüens, Vicente (ed.). Baxar para subir. Colectánea de estudios en memoria de Tomás Buesa Oliver. Zaragoza: Institución Fernando el Católico, 2009, pp. 85-110.

González Ollé, Fernando. «Opciones y preferencias lingüísticas del rey Pedro IV de Aragón». Revista de Filología Española, 2007, vol. 87, n. ${ }^{\circ}$ 2, pp. 293-322.

Irvine, Judith y Susan Gal. «Language ideology and linguistic differentiation». En Kroskrity, P. V. (ed.). Regimes of language ideologies, polities and identities. Santa Fe: School of America Research Press, 2000, pp. 35-83.

Joseph, John E. Eloquence and power: The Rise of Language Standards and Standard Languages. Londres-Nueva York: Frances Pinter \& Blackwell, 1987.

Martínez Pasamar, Concepción y Tabernero Sala, Cristina. Hablar en Navarra. Las lenguas de un reino (1212-1512). Pamplona: Gobierno de Navarra, 2012.

Moral del Hoyo, M. a del Carmen. «El castellano en los orígenes del cambio gramatical: el pretérito imperfecto de la $2^{\mathrm{a}}$ y $3^{\mathrm{a}}$ conjugación $(-i e ́-/$-ia)». En Kabatek, Johannes y Benito Moreno, Carlota (eds.). Lingüistica de corpus y lingüistica histórica iberorrománica, Berlín-Boston: Mouton de Gruyter, 2016, pp. 322-357.

Pato, Enrique. "Queriba una cosa y traíba otra. Los pretéritos imperfectos analógicos en español». Philologica Jassyensia, 2018, vol. 14, n. ${ }^{\circ}$ 2, pp. 83-100.

Rodríguez Molina, Javier. "La reducción fonética avemos cantado > hemos cantado en español antiguo. Nuevos datos y nuevas hipótesis». En Pato, Enrique y Rodríguez Molina, Javier (eds.). Estudios de filología y lingüistica españolas: nuevas voces en la disciplina. Berna: Peter Lang, 2012, pp. 167-234.

Tomás Faci, Guillermo. El aragonés medieval. Lengua y Estado en el reino de Aragón. Zaragoza: Universidad de Zaragoza, 2020. 